\begin{abstract}
ABSTRAK
Terdapat dua isu utama yang muncul mengenai kualitas pada perguruan tinggi; peringkat (rangking) dan akreditasi dalam pengukuran kualitas universitas. Ada beberapa peringkat universitas yang diukur berdasarkan kualitasnya. faktor yang berdampak pada kualitas universitas, namun, mengukur kualitas sebagai aktivitas terisolasi tidak akan mengakibatkan peningkatan kualitas. Penelitian ini membahas pengembangan metodologi TQM untuk meningkatkan kualitas total pada universitas. Tujuan utama dari peneltian ini adalah untuk mengembangkan kerangka metodologi Total Quality Management (TQM) yang memungkinkan universitas swasta dapat mengembangkan dan meningkatkan kualitas melalui rencana implementasi TQM secara efesien dan efektif. Hasil dari penelitian ini adalah sebuah desain kerangka metodologi implementasi model TQM yang berbasis ISO 9000, serta kriteria akreditasi pendidikan tinggi dengan menggunakan lima fase secara berurutan: inisiasi, penilaian, analisis, persiapan dan penerimaan. yang dikombinasikan dengan 7 langkah proses yakni; pemilihan obyek yang akan dievaluasi, menyiapkan kerangka acuan untuk evaluasi, melakukan evaluasi, menyiapkan laporan temuan evaluasi , menyiapkan sebuah rencana aksi dengan langkah-langkah perbaikan, melaksanakan rencana aksi untuk perbaikan berkelanjutan, memantau rencana aksi untuk perbaikan berkelanjutan. Berdasarkan hasil pembahasan, maka dapat disimpulkan bahwa metodologi impelentasi TQM pada universitas swasta yang efisien dan efektif dapat dikembangkan melalui tahapan; mendefinisikan renacana inisiasi, mengukur, menganalisis, mengevaluasi, memperbaiki hasil evaluasi, mengawasi proses pebaikan melalui kegiatan pemantuan perbaikan kualitas yang berkelanjutan.
\end{abstract}

Kata kunci: Desain, Metodologi, Quality, manajemen, universitas swasta

\title{
PENDAHULUAN
}

Keasadaran akan pentingnya pendidikan diIndonesia semakin tinggi. Masyarakat berlomba-lomba untuk mendapatkan pendidikan yang bermutu mulai dari pendidikan dasar sampai pendidikan tinggi. Perguruan tinggi sebagai bagian dari jenjang pendidikan di Indonesia juga berlomba-lomba menjaring mahasiswa yang bermutu. Mutu menjadi salah satu faktor kunci bagi institusi pendidikan termasuk perguruan tinggi untuk dapat bertahan dan terus berkembang. Perguruan tinggi harus proaktif dalam meningkatkan mutunya tidak hanya ditujukan untuk memenuhi aturan-aturan yang ditetapkan pemerintah tetapi harus lebih dari itu yakni memberikan kepuasan kepada konsumennya dalam rangka memenangkan 
persaingan baik di tingkat nasional maupun tingkat internasional. Penerapan total quality management di perguruan tinggi menjadi sangat penting agar dapat selalu memuaskan konsumennya.

Dalam setiap sektor industri manufaktur maupun jasa ada persepsi kualitas. Seperti halnya dengan Universitas merupakan organisasi yang terbuka dan sangat terkait dengan masyarakat. Keberadaan universitas ditengah-tengah masyarakat diperhadapkan pada tantangan yang menuntut adanya perbaikan kualitas secara terus-menerus.

Untuk perguruan tinggi, konsep kualitas bukanlah hal yang baru dan merupakan hal yang terus menerus didiskusikan untuk kepentingan meningkatnya kualitas pendidikan (UNESCO, 2005).Upaya yang dilakukan untuk mengidentifikasi karakteristik sebuah universitas kelas dunia dan menjadikannya sebagai perbandingan (Alden dan Lin, 2004), untuk menemukan tolok ukur sebagai referensi untuk perbaikan kualitas pada setiap universitas apapun saat ini. Namun, ada bukti penelitian tentang bagaimana meningkatkan kualitas sebuah universitas sebagai sebuah organisasi: apa yang perlu dilakukan, atau bagaimana untuk mengatur dan membuat program untuk meningkatkan kualitas universitas.

Ada beberapa model dan kriteria peningkatan dan penjaminan kualitas yang tersedia: walaupun demikian, hanya fokus pada standarisasi apa yang perlu dilakukan, tetapi tidak menggambarkan bagaimana cara melakukannya. Situasi yang sama sudah dihadapi dan dikritik oleh Deming dan Juran ketika mereka memulai Gerakan Kualitas, mereka harus menghadapi kurangnya proses perencanaan kualitas yang terstruktur. Menurut hasil penelitian yang menyatakan bahwa tidak seperti skenario dalam industri, filosofi TQM harus disesuaikan untuk kesuksesan implementasi di pendidikan tinggi. Kerangka kerja TQM yang diusulkan ada enam elemen inti enam kualitas meliputi tujuh langkah aliran proses evaluasi yang menyediakan pedoman sistematis untuk pelaksanaan TQM yang efektif dan efisien dalam pendidikan tinggi. (Sitalakshmi Venkatraman ,2007). Kerangka TQM harus dibangun di atas seperangkat nilai-nilai konsep dasar. Nilai-nilai dan konsep ini memberikan dasar untuk mengintegrasikan persyaratan dan kinerja utama dalam kerangka kualitas. Satu set nilai-nilai dasar yang diusulkan membentuk kerangka TQM dapat diuraikan sebagai berikut:

- Kepemimpinan dan budaya kualitas;

- Perbaikan dan inovasi berkesinambungan dalam proses pendidikan;

- partisipasi dan pengembangan karyawan;

- cepat respon dan pengelolaan informasi; 
- berorientasi pada kualitas pelanggan, dan pembangunan kemitraan, internal maupun eksternal.

Namun, kebutuhan untuk metodologi sangat tidak pernah dirasakan. Tampaknya seolah-olah bahwa begitu banyak bagian dari Metode ini pada umumnya dilakukan diterima begitu saja. Selain itu, belum ada mekanisme yang menyediakan untuk pengembangan metodologi. Di masa lalu, siapa pun yang diperlukan mengembangkan metodologi hanya tergantung pada pemahaman intuitif tentang metodologi dan kemampuan kreatif mereka.

Saat ini, ada dua isu utaman yang muncul mengenai kualitas pada perguruan tinggi; peringkat (rangking) dan akreditasi dalam pengukuran kualitas universitas. Ada beberapa peringkat universitas yang diukur berdasarkan kualitasnya. Sebuah sistem pengukuran kualitas keseluruhan yang baik adalah yang menilai sebuah universitas berdasarkan aspek penting yang berbeda. Ini adalah sarana yang akan menentukan apakah kemajuan sedang dilakukan atau tidak dalam upaya peningkatan kualitas. Dalam hal ini, mengukur kualitas akan memberi kita ide yang baik dari apa yang penting untuk diutamakan, dan karena itu Prosiding Seminar Nasional Manajemen Teknologi XVIII Program Studi MMT-ITS, Surabaya 27 Juli 2013

ISBN : 978-602-97491-7-5 A-14-3

merupakan faktor yang berdampak pada kualitas universitas, namun, mengukur kualitas sebagai aktivitas terisolasi tidak akan mengakibatkan peningkatan kualitas. Penelitian ini membahas pengembangan metodologi TQM untuk meningkatkan kualitas total pada universitas.

\section{Tujuan Penelitian}

Tujuan utama dari penelitian ini adalah mengembangkan metodologi Total Quality Manajemen (TQM) yang efisien dan efektif guna menyediakan instrumen untuk menghasilkan rencana pengelolaan kualitas total pada sebuah universitas swasta. Metodologi TQM akan dikembangkan menggunakan meta-metodologi dan tujuh langkah proses evaluasi yang praktis bagi akademisi untuk menerapkan TQM. Hasil utama dari studi ini akan menjadi Metodologi TQM, yang akan menjadi peta jalan (road map) untuk menghasilkan rencana TQM.

\section{Batasan Masalah}

Mengingat penelitian ini berdasarkan kerangka yang dikembangkan cukup luas, maka penulis membatasi pembahasan pada aspek metodologi yang meliputi inisiasi, penilaian, analisis, persiapan dan penerimaan. Berdasarkan road map penelitian yang telah disusun 
maka pemabahasan dalam artikel ini merupakan bagian dari penelitian yang masih membutuhkan analisis pada waktu mendatang.

Studi Literatur

\section{Definisi Metodologi}

Dalam Kamus Oxford (2010) mendefinisikan metodologi sebagai sebuah sistem metode yang digunakan di dalam kegiatan penelitian tertentu. Dalam kamus bahasa Inggris The Collins (2009) mendefinisikan metodologi sebagai Sistem metode dan prinsip yang digunakan dalam disiplin ilmu tertentu.

Cabang filsafat yang berkaitan dengan ilmu metode dan prosedur. ". Vogt (1999) mendefinisikan metodologi sebagai studi tentang metode dari basis epistemologis untuk masalah pengukuran. Webster (2009) mendefinisikan metodologi sebagai cabang filsafat yang menganalisa prinsip-prinsip dan prosedur penelitian dalam di bidang tertentu. Dalam hal metodoogi akan dibahas dasar-dasar epistemologis pengetahuan, peran nilai-nilai, gagasan sebab-akibat, peran teori dan hubungan empirisnya, definisi dan validitas atau penerimaan dari sumber realitas, penggunaan dan pengurangan peran dan induksi, masalah verifikasi dan pemalsuan, serta isi dan ruang lingkup dari aplikasi dan interpretasi (Sautu, 2005).Terkait penelitian, metodologi memungkinkan sistematisasi metode-metode penelitian yang dilakukan, untuk mencapai hasil yang lebih objektif yang telah diadopsi pada penelitian ilmiah. Jenis penelitian ini adalah cara untuk mengetahui, bahasa umum dari penelitian.

Penelitian ilmiah tidak hanya memungkinkan untuk mengetahui dan menilai cara dan realitas, tetapi juga meningkatkan cara investigasi (Manheim dan Rich, 1946). Oleh karena itu, dianggap sebagai modus untuk mengoreksi pengetahuan yang terus berkembang (Manheim dan Rich, 1946). Penelitian ilmiah adalah eksplisit, sistematis dan terkontrol. Hal ini jelas karena semua aturan untuk mendefinisikan dan menganalisis realitas yang jelas. Ini adalah sistematis karena setiap item tes terkait dengan alasan lain atau observasi. Hal ini dikendalikan karena fenomena dianalisis sejauh mungkin, diamati dengan sangat ketat sebagai status pengetahuan yang memungkinkan (Manheim dan Rich, 1946). Proses penelitian terdiri dari enam tahap yang saling terkait, yakni : perumusan teori, Prosiding Seminar Nasional Manajemen Teknologi XVIII Program Studi MMT-ITS, Surabaya 27 Juli 2013

ISBN : 978-602-97491-7-5 A-14-4

mengoperasionalkan teori, pemilihan teknik penelitian yang sesuai, observasi perilaku, analisis data dan interpretasi hasil (Manheim dan Rich, 1946).

Ada berbagai metode ilmiah seperti, metode induksi-deduksi, metode analisis-sintesis, 
metode objektif-subjektif serta metode statis-dinamis (Muñoz, 1998). Menurut objek studi memungkinkan untuk mengidentifikasi dua jenis utama metodologi, satu berhubungan dengan alam seperti fisika atau kimia dan yang lain yang berkaitan dengan kelompok manusia (seperti ilmu sosial, ilmu bisnis atau perilaku manusia). Untuk kepentingan penelitian ini, definisi operasional metodologi penelitian adalah cara menyatakan masalah dan membuat panduan yang jelas untuk memecahkan masalah, termasuk tujuan, urutan tahapan, kegiatan utama, penyerahan, dan instrumen. Juga metodologi didefinisikan sebagai cara menyatakan masalah dan juga merupakan panduan yang terstruktur didefinisikan dengan baik untuk memecahkan masalah (Creswell et al.., 2003).

Metodologi Hutchinson dan Thomann (1972) mengembangkan Meta-metodologi, yang terdiri dari tujuh langkah untuk mengembangkan metodologi. Adapun langkah-langkah Meta-Metodologi adalah sebagai berikut:

1. Sebutkan tujuan dari metodologi yang diusulkan,

2. Uji tujuan sesuai dengan kriteria sebagai berikut: keinginan, kepraktisan, keunikan, dan operationability,

3. Menganalisis implikasi dari tujuan,

4. Mengoperasionalkan tujuan,

5. Desain prosedur,

6. Uji prosedur, dan

7. Merevisi tujuan dan prosedur, jika perlu.

Total Quality Manajemen

Studi tentang Total Quality Manajemen bukanlah hal baru. Dimulai dengan kualitas, ada kerangka pengetahuan yang telah dibangun, dimulai dengan inspeksi, kemudian ke kualitas, jaminan kualitas, manajemen kualitas, Total Quality dan saat ini Total Quality Manajemen. Terdapat beberapa definisi TQM:

- Tobin (1990) mendefinisikan TQM sebagai usaha terintegrasi total untuk mendapatkan manfaat kompetitif dengan cara secara terus-menerus memperbaiki setiap faset budaya organisasional.

- Witcher (1990) menekankan pada pentingnya aspek-aspek TQM menggunakan penjelasan berikut:

Total: Menandakan bahwa setiap orang dalam perusahaan harus dilibatkan (bahkan mungkin pelanggan dan para pemasok).

* Feigenbaum (1983) mendefinisikan TQM sebagai dampak kontrol kualitas total diseluruh 
organisasi. Feigenbaum (1991) memberikan definisi yang lebih lengkap dari TQM: "sistem kualitas totaldijelaskan sebagai salah satu yang merangkum keseluruhan siklus kepuasan pelanggan dari interpretasi keperluannya terutama pada tahap pemesanan, melalui pasokan produk atau jasa dari hargaekonominya dan pada persepsinya dari produk setelah dia telah menggunakannya sepanjang periodawaktu".

\section{TQM dalam Pendidikan Tinggi}

Dimensi utama pendidikan tinggi yang harus dinilai adalah menghasilkan lulusan untuk memenuhi kebutuhan sumber daya manusia organisasi dan mendorong ke depan batasbatas pengetahuan melalui penelitian (Green, 1994). Saat ini ada skema akreditasi dan lembaga yang hanya memiliki model atau kriteria. Kita dapat menemukannya dalam ABET atau SACS, namun tidak menawarkan metodologi, tetapi hanya satu set persyaratan yang Prosiding Seminar Nasional Manajemen Teknologi XVIII Program Studi MMT-ITS, Surabaya 27 Juli 2013

ISBN : 978-602-97491-7-5 A-14-5

harus dipenuhi universitas saat ini.. Saat ini, universitas menerapkan struktur dan prosedur untuk memenuhi persyaratan, tetapi tanpa ada, urutan, atau usaha terstruktur. Akreditasi bukan sistem peringkat, tetapi proses peer-review yang menjamin kualitas pasca- pendidikan sekolah menengah (ABET, 2010). Akreditasi adalah penelaahan terhadap kualitas lembaga dan program pendidikan tinggi. Dalam akreditasi AS dipandang sebagai proses melalui mana siswa, keluarga, pejabat pemerintah, dan pers dapat memastikan bahwa sebuah institusi atau program ini menyediakan pendidikan yang berkualitas (Chea, 2010).

Menurut hasil penelitian yang menyatakan bahwa Tidak seperti skenario dalam industri, filosofi TQM harus disesuaikan untuk kesuksesan implementasi di pendidikan tinggi. Kerangka kerja TQM yang diusulkan ada enam elemen inti enam kualitas meliputi tujuh langkah aliran proses evaluasi yang menyediakan pedoman sistematis untuk pelaksanaan TQM yang efektif dan efisien dalam pendidikan tinggi. (Sitalakshmi Venkatraman, 2007). Kerangka TQM harus dibangun di atas seperangkat nilai-nilai konsep dasar. Nilai-nilai dan konsep ini memberikan dasar untuk mengintegrasikan persyaratan dan kinerja utama dalam kerangka kualitas. Satu set nilai-nilai dasar yang diusulkan membentuk kerangka TQM dapat diuraikan sebagai berikut:

* kepemimpinan dan budaya kualitas;

* Perbaikan dan inovasi berkesinambungan dalam proses pendidikan;

* partisipasi dan pengembangan karyawan; 
* cepat respon dan pengelolaan informasi;

* berorientasi pada kualitas pelanggan, dan

* pembangunan kemitraan, internal maupun eksternal.

Sebagai bagian dari pelaksanaan TQM ada beberapa metode sistematis / aliran proses yang dapat diadopsi untuk mengevaluasi pengawasan kualitas dari setiap institusi pendidikan tinggi, yang dalam hal ini di uraikan dalam tujuh langkah-langkah sebagaimana berikut ini:

* Langkah 1: Pilih obyek yang akan dievaluasi

* Langkah 2: Siapkan kerangka acuan untuk evaluasi

* Langkah 3: Melakukan evaluasi saja

* Langkah 4: Siapkan laporan temuan evaluasi

* Langkah 5: Siapkan sebuah rencana aksi dengan langkah-langkah perbaikan

* Langkah 6: Melaksanakan rencana aksi untuk perbaikan berkelanjutan

* Langkah 7: Memantau rencana aksi untuk perbaikan berkelanjutan

METODE

Tempat Penelitian

Rencana penelitian ini akan laksanakan pada baeberapa universitas swasta yang akan dijadikan objek di daerah Sulawesi Selatan khususnya Makassar. Dasar pemikiran menjadikan Prosiding Seminar Nasional Manajemen Teknologi XVIII

Program Studi MMT-ITS, Surabaya 27 Juli 2013

ISBN : 978-602-97491-7-5 A-14-6

universitas swasta, karena di wilayah ini sangat banyak universitas swasta yang dipandang belum mengimplementasikan metodologi TQM yang sistematis Pendekatan Solusi

Metodologi yang diusulkan didasarkan pada studi tentang kesuksesan implementasi praktek terbaik model TQM yang dilaksanakan di industri dengan meng analisis unsur-unsur yang digunakan di lingkungan Universitas, sambil mempertimbangkan bahwa Universitas adalah organisasi unik dibandingkan dengan perusahaan dan masalah kualitas pendidikan juga merupakan hal yang unik dalam konteks TQM. Unsur-unsur ini digunakan sebagai masukan untuk pengembangan metodologi. Tujuh langkah Meta-methodology yang kemukakan oleh Thoman (1973) diadopsi untuk pengembangan metodologi TQM.

\section{Rencana Penelitian}

Berdasarkan meta-metodologi, rencana penelitian terurai menjadi 7 langkah-langkah utama seperti yang digambarkan dalam gambar 7. Secara khusus, langkah keenam dalam rencana penelitian akan mengarah pada pengembangan prosedur metodologi TQM. 
Metodologi terdiri dari urutan fase, yang masing-masing mencakup tujuan, aktivitas utama, penyerahan dan peralatan. Setiap aktivitas di setiap tahap terdiri dari sub aktivitas yang dilengkapi dengan input, output, kontrol, dan alat/sumber informasi.

Usulan metodologi TQM ini diterapkan untuk kasus universitas untuk menunjukkan bagaimana sebuah rencana TQM dikembangkan untuk universitas. Ini adalah langkahlangkah proses dalam pengembangan metodologi yang diusulkan. Perencanaan TQM dan metodologi TQM telah dievaluasi oleh orang yang memahami tentang di perguruan tinggi.

Dalam penelitian ini tahapan-tahapan penelitian yang akan dilakukan dalam menyusun sebuah desain metodologi "Total Quality Management) dapat dilihat pada gambar sebagai berikut :

Gambar 1 : Kerangka Aktivitas Penelitian

Prosiding Seminar Nasional Manajemen Teknologi XVIII Program Studi MMT-ITS, Surabaya 27 Juli 2013

ISBN : 978-602-97491-7-5 A-14-7

\section{HASIL DAN PEMBAHASAN}

Pendekatan model

Dalam merumuskan desain model metodologi didasarkan pada rujukan pendukung yang dibutuhkan yang memandang pengembangan desain metodologi dapat dilihat sebagai realisasi sitem produksi. ISO mendefinisikan proses sebagai serangkaian kegiatan yang saling terkait antara satu dengan lainnya untuk mengubah input menjadi output (ISO, 2005). Dengan memperhatikan defenisi ISO tentang proses, maka dalam pembahasan penelitian ini dirancang sebuah pendekatan model sebagai berikut Berdasarkan poendekatan model tersebut di atas, maka dilakukan proses pengumpulan data dengan menggunakan instrumen berupa interview, survey dengan menggunakan kuesioner penelitian. Hasil survey dan penyebaran kuesioner menunjukkan bahwa perguruan tinggi

swasta yang menjadi obyek menginginkan kegiatan proses implementasi manajemen kualitas terpadu berdasarkan nilai bobot dengan pendekatan urutan tingkat kepentingan dapat di uraikan sebagai berikut:

\section{KESIMPULAN DAN SARAN}

\section{Kesimpulan}

Berdasarkan hasil survey dan pembahasan, maka dapat disimpulkan bahwa pada dasarnya perguruan tinggi swasta pada tempat penelitian dapat menerapkan desain model implementasi TQM melalui tahapan inisiasi, penilaian, analisis, persiapan dan penerimaan secara efektif dan efisien. Desain metodologi tersebut dapat dimaksimalkan penerapannya, jika universitas 
swasta melakukan aktivitas utama tahapan metodologi berdasarkan skala prioritas. Pencapain hasil penerapan metodologi dapat dicapai jika didukung oleh instrumen-instrumen (tools) pada setiap tahapan metodologi TQM, serta langkah-langkah aksi perbaikan yang berkelanjutan.

\section{Saran-saran}

1. Berdasarkan hasil pembahasan ini, maka penulis merekomendasikan kiranya universitas swasta menerapkan metodologi implemetasi TQM dalam usaha meningkatkan kualitas proses sebagai institusi pendididikan dan pengajaran.

2. Hasil penelitian ini dapat ditindaklanjuti dalam bentuk penenrlitian yang mengakji secara mendalam implementasi metodologi dengan mengunakan alat kualitas seperti Six Sigma.

\section{DAFTAR PUSTAKA}

ABET Engineering Accreditation Commission (2010) 2010 - 2011 Criteria for Accrediting Engineering Programs. ABET, Inc.

ABET Inc (2010). The Basics: Accreditation

Creswell, J (2005). Educational Research: planning, conducting, and evaluating quantitative and qualitative research.

New Jersey: Pearson Education

Feigenbaum, A.V., Total Quality Control, 3rd ed. Revised, McGraw-Hill, New York, 1991 Shewhart, W.A. (1931) Economic Control of Quality of Manufactured Product.

Manheim, J.Rich, R. (2007) Análisis político empírico método de investigación enciencia política. Madrid: Alianza Editorial.

Sautu, R.(2005) Todo es Teoría: Objetivos y métodos de investigación. Buenos Aires: Lumiere.

Thomann, J. (1973)Meta-methodology: An overview of what it is and how it wasdeveloped.

Tobin, L., The New Quality Landscape: Total Quality Management, Journal of System Management,41(11): 10-14, 1990

Witcher, B., Total Marketing: Total Quality and the Marketing Concept, The Quarterly Review of Marketing, Winter 1990

Wu and Schroeder.( 2011) Customization of Quality Practices: The Impact of Quality Culture. International Journal of Quality \& Reliability Management Vol. 28 ISS Mundiri, A. (2012). PENDIDIKAN TEKNOHUMANISTIK BERBASIS CORE ETHICAL VALUES. At-Tajdid, 1(1), 37-47. 
Mundiri, A. (2015). KOMITMEN ORGANISASIONAL SUMBER DAYA MANUSIA DALAM MENINGKATKAN MUTU PENDIDIKAN PESANTREN. Pedagogik, 3(1), 88105.

Mundiri, A. (2016). THE LEADERSHIP OF HEADMASTER IN BUILDING A WORK CULTURE BASED ON PESANTREN. In International Conference on Education and Training (pp. 1-7). Malang: Faculty of Education State University of Malang.

Mundiri, A. (2017). Organizational Culture Base On Total Quality Management In Islamic Educational Institution. ADRI International Journal Of Islamic Studies and Social Sciences, $1(1), 1-11$.

Mundiri, A., \& Zahra, I. (2017). Corak Representasi Identitas Ustadz dalam Proses Transmisi Pendidikan Karakter di Pesantren. Jurnal Pendidikan Islam, Vol. 2, No, 21-35. 